\title{
Comparison of Soluble fms-Like Tyrosine Kinase-1 (SFLT-1) between Normal and Severe Pre-eclampsia in Pregnant Women, Medan, Indonesia
}

\author{
Rebecca Rumesty Lamtiar'1), Erna Mutiara'), Sarma N Lumban Raja3) \\ 1)Department of Physiology, Faculty of Medicine, HKBP Nommensen University, Medan \\ 2)Department of Biostatistics, Faculty of Public Health, North Sumatra University, Medan \\ 3)Department of Obstetrics and Gynecology, Haji Adam Malik Hospital, Medan
}

\begin{abstract}
Background: The pathogenesis of pre-eclampsia as a primary cause of mortality among pregnant women remains unclear. It was suggested that angiogenic factors such as Soluble fms-Like Tyrosine Kinase-1 (SFLT-1) play an important role in the causal mechanism of pre-eclampsia/ eclampsia. This study aimed to compare the SFLT-1 level in pre-eclampsia/ eclampsia in pregnant women with that in normotensive pregnant women.

Subjects and Method: This was an analytic observational conducted at three hospitals: Haji Adam Malik, Pirngadi, and Sundari Hospitals, Medan, Indonesia, from September to December 2014. A total sample of 60 pregnant women of the third trimester, including those with severe preeclampsia/ eclampsia and normotensive women, was selected for this study. The level of serum SFLT-1 was measured by ELISA method. The difference in mean of serum SFLT-1 levels between the two groups was tested by Mann-Whitney.

Results: The mean of serum SFLT-1 level in women with preeclampsia was higher (mean=1692.69pg/ ml; $\mathrm{SD}=540.64$ ) than that in normotensive women (mean=1348.52pg/ ml; $\mathrm{SD}=649.83)$. This difference was statistically significant $(\mathrm{p}=0.040)$.

Conclusion: Level of serum SFLT-1 in women with severe pre-eclampsia/ eclampsia is significantly higher than that of normotensive women.
\end{abstract}

Keywords: serum SFLT-1, pre-eclampsia, pregnant women

\section{Correspondence:}

Rebecca Rumesty Lamtiar. Department of Physiology, Faculty of Medicine, HKBP Nommensen University, Medan.

\section{BACKGROUND}

Thehigh maternal mortality rate is considered as one of the world's health problems. Maternal mortality rate in developing countries is 15 times higher than in developed countries (WHO, 2012). Indonesia as one of the developing countries still contributes in high maternal mortality rate. In the past five years, the rate of maternal mortality in Indonesia is increasing (BKKBN, 2012).

As much as $24 \%$ of cases that cause maternal death is pre-eclampsia (Kemenkes, 2010). Around 10 of pregnancies world- wide are associated with pre-eclampsia (WHO, 2011). In Indonesia, pre-eclampsia cases happen to $5-10 \%$ of the number of pregnancies (Kemenkes, 2011). According to North Sumatra Health Office data (2011), maternal mortality rate as the result of preeclampsia in Pirngadi General Hospital Medan, during 2008-2010 is increasing.

Up to currently the pathogenesis of pre-eclampsia is not yet clearly discovered. There are a lot of theories state that there is a relationship between pre-eclampsia with placentation process. Cytotrophoblast cell which fails to invade spiral artery of a mo- 
their lead to the emergence of trophoblast injury and placental ischemia (Wang et al., 2009). Ischemic placenta is predicted secreting a factor of anti-angiogenic soluble fms Like Tyrosine Kinase-1 (SFLT-1) and afterward blood vessel endothelium is obstructed in performing angiogenesis. Placenta of pre-eclampsia patients produces SFLT-1, an anti-angiogenic factor which obstructs angiogenesis process by binding proangiogenic compound, among others are Vascular Endothelial Growth Factor (VEGF) and Placental Growth Factor (PLGF) (Andraweera et al., 2012; Wang et al., 2008; Mutter and Karumanchi, 2008). As the result of placental ischemia, dysfunction of endothelium occurs. Endothelium dysfunction manifests in a form of tissue damage and multiple organs damage on mother and fetus which is progressive in nature (Karumanchi et al., 2007; Wang et al., 2009; Murphy et al., 2013).

Numerous studies are emerging about how the level of angiogenesis factors is on pregnant women with pre-eclampsia. Imbalance between angiogenic and antiangiogenic in maternal circulation is considered contribute in severe pre-eclampsia pathophysiology (Maynard et al., 2003; Eiland, 2012) Some studies also stated that SFLT-1 in serum is found on pregnant women with pre-eclampsia in the early stage of pregnancy up to the middle stage (Kusanovic, 2009; $\mathrm{Yu}$ et al., 2010). Compared to normal pregnancy, the level of sFLT-1 is higher in serum of women with pre-eclampsia (Levine, 2004; Verlohren, 2012)

The study aims to compare the level sFLT-1 on women with severe pre eclampsia/ eclampsia and normal pregnant women.

\section{SUBJECTS AND METHOD}

The study was analytical study by using matched case control design. Sample of the study was women with intrauterine pregnancy, living and single fetus, with gestational age was more than 28 weeks, who was diagnosed with or without severe preeclampsia/ eclampsia by Obstetrician and Gynecologist of Haji Adam Malik Hospital Medan, Dr. Pirngadi Hospital, Sundari General Hospital Medan and recorded as patients in their status cards. The study excluded pregnant women who had history of diabetes mellitus, kidney abnormalities, history of heart disease, immunity deviance, and pregnancies associated with congenital disorder on fetus.

Sixty research samples were collected by consecutive method and divided into 2 groups that were 30 case samples (group of pregnant women with severe pre-eclampsia/ eclampsia) and 30 of control samples (group of women with normal pregnancy). During sample collection, matching process was conducted between case group and control group in the terms of maternal age, gestational age, and parity status.

The study had obtained approval from Health Research Ethics Committee of Faculty of Medicine, North Sumatra University (Inform Consent).

SFLT-1 level in blood serum was measured in Spectrum International laboratory Medan by using quantitative sandwich enzyme immuno assay method.

The obtained data would be edited, coded, and afterward recorded into computer. Initially, Kolmogorov-smirnov normality test was conducted on numerical data, it was continued with univariate analysis. Mann Whitney was used to know the comparison of SFLT-1 level on both groups

\section{RESULTS}

\section{Characteristics of Patients}

Respondents of the study were women in the third semester of pregnancy, who were 
divided into two groups, among others were 30 pregnant women with severe preeclampsia and the others were 30 women with normal pregnancy as control group. Matching process was conducted on both groups in the terms of age, gestational age, parity status. The most range of age of the respondents was 20-35 years old (83.3\%), with the most gestational age ranged from $37-38$ weeks $(50 \%)$ and the parity status was nulliparous women (46.7\%).

Table 1. Sample characteristics

\begin{tabular}{|c|c|c|c|c|}
\hline \multirow[t]{2}{*}{ Characteristics } & \multicolumn{2}{|c|}{$\begin{array}{l}\text { Pre-eclampsia } \\
\text { /eclampsia }\end{array}$} & \multicolumn{2}{|c|}{ Normal Pregnancy Group } \\
\hline & $\mathrm{n}$ & $\%$ & $\mathrm{n}$ & $\%$ \\
\hline \multicolumn{5}{|l|}{ Sample } \\
\hline - 20-35 years & 25 & $83 \cdot 3$ & 25 & 83.3 \\
\hline$\bullet \quad>35$ years & 5 & 16.7 & 5 & 16.7 \\
\hline \multicolumn{5}{|l|}{ Pregnancy age } \\
\hline - 28-32 week & 2 & 6.7 & 2 & 6.7 \\
\hline - 33-34 week & 2 & 6.7 & 2 & 6.7 \\
\hline - $35-36$ week & 11 & 36.7 & 11 & 36.7 \\
\hline - $37-38$ week & 15 & 50.0 & 15 & 50.0 \\
\hline \multicolumn{5}{|l|}{ Parity Status } \\
\hline - Nulliparous & 14 & 46.7 & 14 & 46.7 \\
\hline - Primiparous & 6 & 20.0 & 6 & 20.0 \\
\hline - Multiparous & 10 & $33 \cdot 3$ & 10 & 33.3 \\
\hline
\end{tabular}

Table 2 presents that the mean value of SFLT-1 level on group of women with severe pre-eclampsia/ eclampsia is 1692.69 $\mathrm{pg} / \mathrm{ml}$. Data of SFLT- 1 level is data which is not normally distributed based on Kolgorov-smirnov normality test therefore the medium value of SFLT-1 level is presented.
The study result shows that medium value of SFLT-1 level on group of pregnant women with severe pre-eclampsia/ eclampsia is as much as $1901.94 \mathrm{pg} / \mathrm{ml}$ whereas on group of women with normal pregnancy is $1474.05 \mathrm{pg} / \mathrm{ml}$.

Table 2. SFLT-1 level characteristics

\begin{tabular}{lcccccc}
\hline \multicolumn{1}{c}{ Variables } & $\mathrm{n}$ & Min & Max & Mean & $\begin{array}{c}\text { Standard } \\
\text { Deviation }\end{array}$ & $\mathrm{p}$ \\
\hline SFLT-1 (pg/ml) & 60 & 16.26 & 2077.60 & 1520.61 & 617.53 & 0.040 \\
$\begin{array}{l}\text { - Normal pregnancy } \\
\text { - Pre-eclampsia/ }\end{array}$ & 30 & 16.26 & 2054.72 & 1348.52 & 649.83 & \\
$\quad$ eclampsia & 30 & 181.84 & 2077.60 & 1692.69 & 540.64 & \\
\hline
\end{tabular}

\section{Comparison of SFLT-1 Level}

Based on Figure 1 it can be seen that SFLT1 level on group of pregnant women with severe pre-eclampsia/eclampsia is higher than on group of women with normal preg-
nancy.Mann-Whitney test result shows that SFLT-1 level on group of pregnant women with severe pre-eclampsia/ eclampsia is significantly higher compared to group of women with normal pregnancy $(\mathrm{p}=0.044)$. 


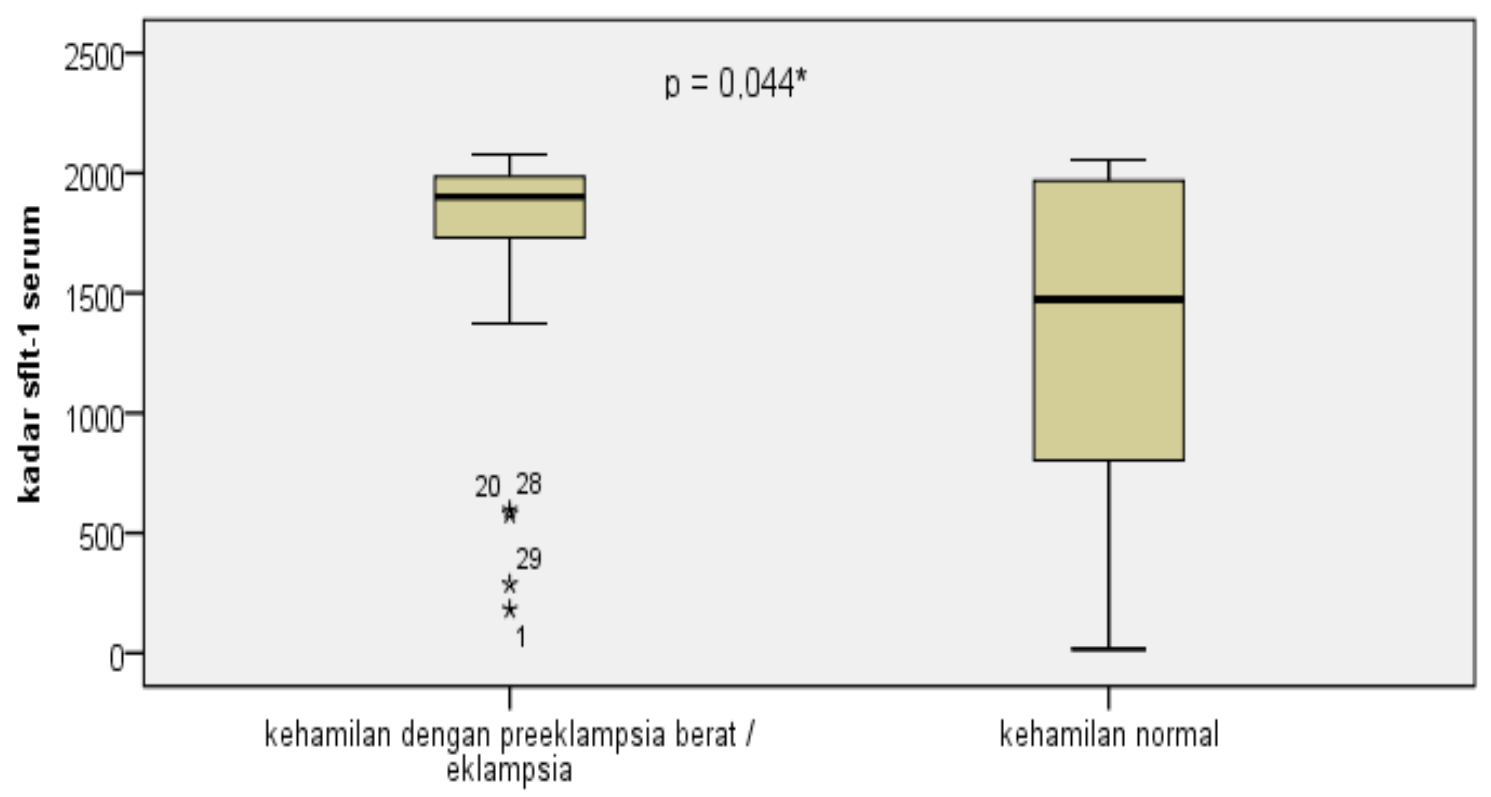

diagnosis

* Significant by Mann-Whitney test

Figure 1. Comparison Chart levels of SFLT-1

\section{DISCUSSION}

In this study, the most characteristic of pregnant women with pre-eclampsia/ eclampsia was in 20-35 year old age group. The study of Kashanian et al (2011) in Iran stated that the most characteristic of pregnant women with pre-eclampsia/ eclampsia was in 20-30 years old of age. Kashanian et al., also stated that pregnant women who are more than 30 years old have bigger risk to endure pre-eclampsia than younger pregnant women. It is also in accordance with the study that stated that the older a woman then she will endure the higher risks to childbirth complications, one of them is pre-eclampsia (Jacobbson, 2004).

The study showed that most of the samples were nulliparous. It is in accordance with the study which states that one of the risk factors for pre-eclampsia was the nulliparous status on women (Odegard, 2000).

In this study it obtained the mean value of SFLT-1 level on group of pregnant women in the third trimester with preeclampsia/ eclampsia was $1692.69 \mathrm{pg} / \mathrm{ml}$ whereas on group of women with normal pregnancy was $1348.52 \mathrm{pg} / \mathrm{ml}$. In this study it also obtained the medium value of SFLT1 level on group of pregnant women in the third trimester with severe pre-eclampsia/ eclampsia was $1901.935 \mathrm{pg} / \mathrm{ml}$ whereas on group of women with normal pregnancy was $1474.05 \mathrm{pg} / \mathrm{ml}$. The result of MannWhitney test showed that the level of SFLT1 on pregnant women with severe preeclampsia/ eclampsia was significantly higher that on group of women with normal pregnancy $(\mathrm{p}=0.044)$. It is in accordance with a study which states that there is a significant difference between the level of SFLT-1 on pre-eclampsia pregnant women with normal pregnant women (Maynard, 2003; Levine et al., 2004; Widmer et al, 2007). Levine et al., states that the average rise of SFLT-1 level on pre-eclampsia escalates up to three times than the value on normal pregnant women. The escalation 
happens after the $25^{\text {th }}$ week of pregnancy (Widmer et al., 2007).

The level of SFLT-1 on normal pregnant women will start to increase in the $20^{\text {th }}-3 \mathrm{O}^{\text {th }}$ week of pregnancy and later will rapidly escalate in the $35^{\text {th }}-39^{\text {th }}$ week of gestation age. However the increasing of SFLT-1 on group of pregnant women with pre-eclampsia happens bigger than normal pregnant women (Levine, 2004). SFLT-1 as antiangiogenic factor is found more in placenta and serum of pregnant women with pre-eclampsia (Maynard, 2003). On pregnant women with pre-eclampsia there is found placenta which endures ischemia. The ischemic placenta produces more SFLT-1 (Smith and Wear, 2009). Masabumi (2012) conveys that hypoxia condition found in pre-eclampsia placenta have significant effect in SFLT-1 regulation. The reduction of utero-placenta blood stream leads to the rise of SFLT-1 ekspression. It is predicted there is HIF-1 $\alpha$ contribution in the rise of SFLT-1. Hypoxia condition on placenta stimulates the activity of HIF-1a, afterward HIF-1a increase the expression and secretion of SFLT-1 (Zhou et al., 2011).

High level of SFLT-1 on the circulation hampers the work of pro-angiogenic factors (Levine, 2004; Matsubara, 2009). The imbalance angiogenic leads to endothelium dysfunction. The condition generates the emergence of clinical manifestation such as hypertension, coagulation disorder and proteinuria. It probably may explain pathophysiology of clinical manifestation which emerges on severe pre-eclampsia/ eclampsia.

The conclusion derived from the study was that SFLT-1 level in group of pregnant women with pre-eclampsia was higher than on group of normal pregnant women.

The study was narrowly conducted on women in the third trimester of their preg- nancy therefore the level of SFLT-1 obtained was the illustration of pre-eclampsia occurrence process. It is expected to conduct further study by observing the changes of SFLT-1 level from the second trimester up to the end of the pregnancy and obtain screening value toward the clinical symptoms deterioration as the result of preeclampsia. Eventually a management can be conducted in preventing the deterioration as the result of pre-eclampsia from prenatal period, thus will give value in the effort to suppress maternal mortality rate.

\section{REFERENCE}

Alice W, Sarosh R, S Ananth K (2008). Preeclampsia: The Role of angiogenic Factors in Its Pathogenesis. Physiology 24: 147-158.

Andraweera PH, Dekker GA, C Roberts T (2012). The Vascular Endothelial Growth Factor Family in Adverse Pregnancy Outcomes. Human Reproduction Update 18: 436-457.

Eiland E, Nzerue C, Faulkner M (2012). Review Article Preeclampsia. Journal of Pregnancy 1-7.

Karumanchi SA, Epstein MH (2007). Placental ischemia and Soluble. fms-Like Tyrosine Kinase 1: Cause or Consequence of Preeclampsia. Kidney International 71: 959-961.

Levine R J, Lam C, Qian C, Yu KF, Maynard SE, Sachs B P, Sibai BM, Epstein M H, Romero Roberto, Thadhani Ravi, Karumanchi SA (2004). Soluble Endoglin and Other Circulating antiangiogenic Factors in Preeclampsia. The New England Journal of Medicine 355: 992-1005.

Markus S, Dogan C, Canan B, Ulrich K, Gllhaus A, Rainer K, Bauer SK 
(2009). Placental Growth Factor: A

Gynakol Geburt shilfliche Rundsch 49: 94-99.

Marni J, Natasha N, Christine LR, Ruth H, Jonathan M, Ashton M, Anthony W (2011). Levels of Soluble fms-lik Tyrosine Kinase and One in the First Trimester of Pregnancy Outcomes: A Systematic Review. Reproductive Biology and Endrocinology 9: 1-8.

Matsubara K, Yuko M, Ito M (2009). The Utility of Vascular Dysfunction Studies in The Prediction and Prevention of Preeclampsia: A Historical Review. Vascular Disease Prevention 6: 163169.

Maynard SE, Min JY, Merchan J, Lim Kee Rights, Li Jianyi, Mondal S, Libermann TA, JP Morgan, Sellke FW, Stillman IE, Epstein FH, Sukhatme VP, and Karumanchi SA (2003). Excess Placental Soluble fms-Like Tyrosine Kinase 1 (SFLT-1) may Contribute to Endothelial Dysfunction, Hypertension and Proteinuria in Preeclampsia. J. Clin. Invest 1(11): 649658.

Ministry of Health (2008). Maternal Mortality. Downloaded from: http:// menegpp.go.id/v2/index.php/datadaninf ormasi/kesehatan?download $=23 \% 3 \mathrm{~A}$ ngka-kematian-ibu-melahirkanakiWHO.

Ministry of Health (2012). Trends in Maternal Mortality from 1992 to 2012 in 2012 IDHS.
Predictive Marker for Pre-eclampsia.

$\mathrm{MoH}$ (2011). The Indonesia Health Profile Data. Downloaded from http://www. depkes.go.id.

Murphy SR, Lamarca BBD, Parrish M, Cockrell K, Granger JP (2013). Control of Soluble Fms tyrosine Like-1 (SFLT-1) Production Response to Placental ischemia/ hypoxia: Role of Tumor Necrosis Factor. American Journal Physioregul integr Comp Physiol 304: R130-R135.

Mutter WP, Karumanchi SA (2008). Molecular Mechanisms of Preeclampsia. Microvascular Research, 75: 1-8.

Odegård RA, Vatten LJ, Nilsen ST, Vesen KA, Austgulen R (2000). Risk factors and clinical manifestations of preeclampsia. BJOG 107: 1410-6.

The National Population and Family Planning (2012). The Indonesian Demographic and Health Survey. Jakarta; Indonesia; 213 things.

UNICEF (2012). Summary of Maternal and Child Health Study. Jakarta: 1-6.

Verlohren S, Herraiz I, Lapaire O, Schlembach D, Moertl M, Zeisler Harald, Calda P, Holzgreve W, A Galindo, Engels $\mathrm{T}$, Denk B, Stepan H (2011). The SFLT-1/ PlGF ratio in Different Types of hypertensive. The New England Journal of Medicine 1(5): 9-15. 